Research article Open Access

\title{
Susceptibility of rheumatoid arthritis synovial fibroblasts to FasL- and TRAIL-induced apoptosis is cell cycle-dependent
}

\author{
Noreen Pundt ${ }^{1}$, Marvin A Peters ${ }^{1}$, Christina Wunrau ${ }^{1}$, Simon Strietholt ${ }^{1}$, Carsten Fehrmann², \\ Katja Neugebauer ${ }^{1}$, Christine Seyfert ${ }^{3}$, Frans van Valen ${ }^{1}$, Thomas Pap ${ }^{1}$ and Ingmar Meinecke ${ }^{1,4}$
}

\begin{abstract}
${ }^{1}$ Institute of Experimental Musculoskeletal Medicine, University Hospital Muenster, Domagkstr. 3, Muenster, 48149, Germany
${ }^{2}$ Institute of Medical Microbiology, University Hospital Muenster, Domagkstr. 10, Muenster, 48149, Germany

3Department of Orthopaedic Surgery, Zeisigwaldkliniken Bethanien Chemnitz, Zeisigwaldstr. 101, Chemnitz, 09130, Germany

${ }^{4}$ Department of Orthopaedic Surgery, Park-Krankenhaus Leipzig-Suedost GmBH, Struempellstr. 41, Leipzig, 04289, Germany
\end{abstract}

Corresponding author: Thomas Pap, thomas.pap@uni-muenster.de

Received: 13 May 2008 Revisions requested: 25 Jun 2008 Revisions received: 24 Nov 2008 Accepted: 5 Feb 2009 Published: 5 Feb 2009

Arthritis Research \& Therapy 2009, 11:R16 (doi:10.1186/ar2607)

This article is online at: http://arthritis-research.com/content/11/1/R16

(c) 2009 Pundt et al.; licensee BioMed Central Ltd.

This is an open access article distributed under the terms of the Creative Commons Attribution License (http://creativecommons.org/licenses/by/2.0), which permits unrestricted use, distribution, and reproduction in any medium, provided the original work is properly cited.

\begin{abstract}
Introduction The rheumatoid arthritis (RA) synovium is characterised by the presence of an aggressive population of activated synovial fibroblasts (RASFs) that are prominently involved in the destruction of articular cartilage and bone. Accumulating evidence suggests that RASFs are relatively resistant to Fas-ligand (FasL)-induced apoptosis, but the data concerning tumour necrosis factor-related apoptosis-inducing ligand (TRAIL) have been conflicting. Here, we hypothesise that the susceptibility of RASFs to receptor-mediated apoptosis depends on the proliferation status of these cells and therefore analysed the cell cycle dependency of FasL-and TRAIL-induced programmed cell death of RASFs in vitro.
\end{abstract}

Methods Synovial fibroblasts were isolated from patients with RA by enzymatic digestion and cultured under standard conditions. Cell cycle analysis was performed using flow cytometry and staining with propidium iodide. RASFs were synchronised or arrested in various phases of the cell cycle with $0.5 \mathrm{mM}$ hydroxyurea or $2.5 \mu \mathrm{g} / \mathrm{ml}$ nocodazol and with foetal calf serum-free insulin-transferrin-sodium selenite supplemented medium. Apoptosis was induced by stimulation with $100 \mathrm{ng} / \mathrm{ml}$ FasL or $100 \mathrm{ng} / \mathrm{ml}$ TRAIL over 18 hours. The apoptotic response was measured using the Apo-ONE ${ }^{\circledR}$ Homogenous Caspase-3/7 Assay (Promega GmbH, Mannheim, Germany) and the Cell Death Detection (ELISAPlus) (enzyme-linked immunosorbent assay) (Roche Diagnostics $\mathrm{GmbH}$, Mannheim,
Germany). Staurosporin-treated cells $(1 \mu \mathrm{g} / \mathrm{ml})$ served as a positive control. Expression of Fas and TRAIL receptors (TRAILR1-4) was determined by fluorescence-activated cell sorting analysis.

Results Freshly isolated RASFs showed only low proliferation in vitro, and the rate decreased further over time, particularly when RASFs became confluent. RASFs expressed Fas, TRAIL receptor-1, and TRAIL receptor-2, and the expression levels were independent of the cell cycle. However, the proliferation rate significantly influenced the susceptibility to FasL- and TRAIL-induced apoptosis. Specifically, proliferating RASFs were less sensitive to FasL- and TRAIL-induced apoptosis than RASFs with a decreased proliferation rate. Furthermore, RASFs that were synchronised in $S$ phase or $G_{2} / M$ phase were less sensitive to TRAlL-induced apoptosis than synchronised RASFs in $\mathrm{G}_{0} / \mathrm{G}_{1}$ phase.

Conclusions Our data indicate that the susceptibility of RASFs to FasL- and TRAIL-induced apoptosis depends on the cell cycle. These results may explain some conflicting data on the ability of RASFs to undergo FasL- and TRAIL-mediated cell death and suggest that strategies to sensitise RASFs to apoptosis may include the targeting of cell cycle-regulating genes.

2 n DNA: diploid chromosomes; 4 n DNA: tetraploid chromosomes; DMEM: Dulbecco's modified Eagle's medium; EDTA: ethylenediaminetetraacetic acid; ELISA: enzyme-linked immunosorbent assay; FACS: fluorescence-activated cell sorting; FasL: Fas ligand; FCS: foetal calf serum; HU: hydroxyurea; ITS: insulin-transferrin-sodium selenite; NF-кB: nuclear factor-kappa-B; OD: optical density; PBS: phosphate-buffered saline; RA: rheumatoid arthritis; RASF: rheumatoid arthritis synovial fibroblast; RFU: relative fluorescence units; TNF: tumour necrosis factor; TRAIL: tumour necrosis factorrelated apoptosis-inducing ligand. 


\section{Introduction}

Rheumatoid arthritis (RA), a chronic disease of incompletely understood aetiology, is characterised primarily by the progressive destruction of articular structures. Its pathogenesis is governed by the concerted action of several cell types that create signs and symptoms characteristic for RA. Accumulating evidence indicates that, in addition to macrophages and $\mathrm{T}$ cells, activated RA synovial fibroblasts (RASFs) play a major role in both initiating and driving the disease [1-4]. Not only do RASFs with an aggressive phenotype increase in number, their activation also results in the production of proinflammatory mediators and matrix-degrading enzymes and in alterations of programmed cell death [3-5].

Programmed cell death, or apoptosis, is central for both development and tissue homeostasis of metazoans. Therefore, aberrations of this process may lead to a variety of human pathologies, including cancer, autoimmune diseases, and neurodegenerative disorders. Apoptosis can be induced by members of the tumour necrosis factor (TNF) receptor family through the recruitment of an intracellular membrane-associated complex of proteins (death-inducing signaling complexes, or DISCs), which leads to a cytoplasmic release of active caspase- 8 and subsequent activation of the apoptotic cascade $[6,7]$. Among these death receptors, Fas/CD95 and its specific ligand FasL/CD95L were demonstrated to be of importance, and it was shown that stimulation of RASFs with FasL initiates proapoptotic signals $[8,9]$. However, several studies with cultured RASFs showed that stimulation of RASFs with Fas-activating ligands induced apoptosis in only a small percentage of cells, and several mechanisms have been identified that prevent RASFs from Fas-mediated cell death [10-16]. Actually, several studies have shown that RASFs undergo less FasL-induced apoptosis than osteoarthritis synovial fibroblasts and therefore RASFs has been termed relatively resistant to FasL-induced apoptosis. As shown previously, fibroblasts in RA synovium express both TNF- $\alpha$ receptors and Fas, and their ligands have been detected in colocalised macrophages and T cells [17-19].

TNF-related apoptosis-inducing ligand (TRAIL), another member of the TNF superfamily of apoptosis-inducing ligands, can bind to five receptors. Among them, TRAIL-R3 (DcR1) and TRAIL-R4 (DcR2) act as membrane-anchored decoy receptors, whereas TRAIL-R1 (DR4) and TRAIL-R2 (DR5) contain a cytoplasmic death domain and transmit proapoptotic signals into cells [20]. In addition, osteoprotegerin, a soluble decoy receptor of the ligand for the receptor activator of nuclear factor-kappa-B (NF- $\kappa$ B) (RANKL), has been shown to bind TRAIL $[21,22]$. Apoptosis can be induced upon binding of TRAIL to DR4 and DR5 and subsequent activation of different caspases. On the other hand, studies suggest that binding of TRAIL to these receptors can also induce proliferation through activation of the NF- $\kappa B$ signalling pathway $[23,24]$, and it appears that the ability of TRAIL to trigger either apoptosis or cell survival depends on the cell type [25].

The in vitro data concerning TRAIL-induced apoptosis in RASFs have been conflicting. Morel and colleagues [25] showed that exposure to TRAIL induced apoptosis in only $30 \%$ of RASFs within 24 hours whereas surviving cells proliferated in a TRAIL dose-dependent manner. In contrast, Ichikawa and colleagues [26] documented TRAIL (anti-DR5 antibody)-induced apoptosis of RA synovial cells with $80 \%$ of the cells being killed. In both studies, RASFs showed constitutive expression of TRAIL receptor-2 (DR5) as the main mediator of TRAIL-induced stimulation. In addition, Morel and colleagues [25] could show the expression of TRAIL-R1 (DR4). Here, we hypothesise that the susceptibility of RASFs to receptor-mediated apoptosis depends on the proliferation state of these cells. Therefore, we analysed the cell cycle dependency of FasL- and TRAIL-induced programmed cell death of RASFs in vitro.

\section{Materials and methods \\ Patients and tissue samples}

Samples of synovial membrane from patients with RA (according to the 1987 revised American College of Rheumatology criteria) were obtained at joint replacement surgery within an ongoing national tissue bank project with the 'Assoziation für Rheumatologische Orthopädie' (ARO) of the German Society of Rheumatology (DGRh) and provided by the Department of Orthopaedic Surgery of St. Joseph Hospital (Sendenhorst, Germany), the Department of Orthopaedic Surgery of the University of Magdeburg School of Medicine (Magdeburg, Germany), and the Department of Orthopaedic Surgery (KMGKliniken Kyritz, Germany). Approval from the local ethics committee was obtained prior to starting the study. Fibroblasts were isolated by digesting synovial tissue with $1.5 \mathrm{mg} / \mathrm{ml}$ Dispase II (Roche Diagnostics GmbH, Mannheim, Germany) and cultured in complete Dulbecco's modified Eagle's medium (DMEM supplemented with $10 \%$ foetal calf serum [FCS], Invitrogen Corporation, Carlsbad, CA, USA, and penicillin/streptomycin, PAA, Pasching, Austria) as described previously [27]. Fibroblasts were used in passages 4 to 8 .

\section{Fluorescence-activated cell sorting analysis}

Flow cytometric analysis of cell cycle was performed as described previously [28]. Briefly, cells were detached with 1 $\mathrm{mM}$ ethylenediaminetetraacetic acid (EDTA) and suspended in fluorescence-activated cell sorting (FACS) buffer (phosphate-buffered saline [PBS] supplemented with 5\% FCS and $0.1 \% \mathrm{NaN}_{3}$ ). Cell cycle analysis was performed by incubation of cells with propidium iodide $(40 \mu \mathrm{g} / \mathrm{ml}$ propidium iodide, 100 $\mu \mathrm{g} / \mathrm{ml}$ RNase in PBS) for up to 2 days and subsequent flow cytometry (FACScalibur; BD Biosciences, San Jose, CA, USA). To arrest RASFs in $\mathrm{G}_{2} / \mathrm{M}$ phase, cells were treated with nocodazol $(2.5 \mu \mathrm{g} / \mathrm{ml}$ in DMEM for 18,24 , or 36 hours; Calbiochem, Darmstadt, Germany). Furthermore, randomly growing 
cultures of RASFs were synchronised with $0.5 \mathrm{mM}$ hydroxyurea (HU) (Sigma-Aldrich, Steinheim, Germany) in DMEM and incubated at $37^{\circ} \mathrm{C}$ for 6 hours. Cells were washed with PBS and suspended in fresh complete DMEM. Synchronised RASFs were incubated at $37^{\circ} \mathrm{C}$ and samples $(0,18,24,30$, 42 , and 48 hours) thereof were analysed for cell cycle by propidium iodide staining as described above. In addition, RASFs were arrested in $G_{0} / G_{1}$ phase by serum deprivation. To this end, cultures of RASFs were incubated with DMEM supplemented with $1 \times$ insulin-transferrin-sodium selenite (ITS) supplement (100x) (Sigma-Aldrich) $[29,30]$ for up to 10 days (0, 3,8 , and 10 days) following incubation with complete medium for 1 or 2 days (9/1, 9/2 days).

\section{Analysis of Fas- and TRAIL-receptor expression}

Surface expression of Fas and TRAIL receptors (TRAILR1-4) on RASFs was determined by flow cytometry as described [31]. Briefly, $1 \times 10^{5}$ cells were labelled with $0.5 \mu \mathrm{g}$ of mouse anti-TRAILR1-4 (Alexis Biochemicals, Lörrach, Germany), mouse anti-Fas antibodies, or mouse anti-lgG in FACS buffer containing $5 \mathrm{mM}$ EDTA for 40 minutes at $4^{\circ} \mathrm{C}$. These cells were incubated with biotin-conjugated goat anti-mouse, phycoerythrin-conjugated anti-goat, or fluorescein isothiocyanateconjugated anti-mouse antisera for 30 minutes at $4^{\circ} \mathrm{C}$. Stained cells were fixed and $1 \times 10^{4}$ viable cells were analysed by flow cytometry using standard settings.

\section{Induction and measurement of apoptosis}

Apoptosis was induced at different density states or cell cycle phases by incubation of cells with $100 \mathrm{ng} / \mathrm{ml}$ FasL (Bender MedSystems, Vienna, Austria) or $100 \mathrm{ng} / \mathrm{ml}$ TRAIL (Pepro Tech, Rocky Hill, NJ, USA) in $100 \mu \mathrm{L}$ of complete DMEM or DMEM for 18 hours. The apoptotic response was measured by Cell Death Detection (ELISAPlus) (enzyme-linked immunosorbent assay) (Roche Diagnostics $\mathrm{GmbH}$ ) and the ApoONE ${ }^{\circledR}$ Homogeneous Caspase-3/7 Assay (Promega GmbH, Mannheim, Germany) in accordance with the instructions of the manufacturer. Staurosporin-treated cells $(1 \mu \mathrm{g} / \mathrm{ml}, 8$ hours) served as a positive control.

\section{Statistical analysis}

Data shown are mean \pm standard deviation. Statistical analysis was performed using GraphPad Prism Software version 4.0 (GraphPad Software Inc., San Diego, CA, USA). Differences between groups were examined for statistical significance using the Mann-Whitney test, and a $P$ value of less than 0.05 was considered statistically significant.

\section{Results}

Proliferation of rheumatoid arthritis synovial fibroblasts First, we analysed DNA content by FACS analysis to determine the proliferation rate of RASFs. Early-cultured RASFs exhibited a proliferation rate of $13.01 \%$, according to cells with a DNA content of greater than $2 \mathrm{n}$ (Figure $1 \mathrm{a}$, representative histogram, and Figure $1 \mathrm{c}, \mathrm{DNA}$ content in $\mathrm{S}$ and $\mathrm{G}_{2} / \mathrm{M}$ phases, $\mathrm{n}=11$ ). $\sim 2 \mathrm{n}$ DNA refers to the normal DNA content in the interphase $\left(\mathrm{G}_{0} / \mathrm{G}_{1}\right.$ phase, diploid) of RASFs [32]. Confluent RASFs ( $100 \%$ confluent, $10^{4}$ cells) exhibited a proliferation rate of $6.53 \%$ (Figure $1 \mathrm{~b}$, representative histogram, and Figure $1 \mathrm{c}, \mathrm{n}=5$ ), significantly lower compared with early-cultured RASFs (Figure 1c, $P=0.0028$ ). Nocodazol, the microtubule-destabilising agent that disrupts spindle assembly and impedes re-entry into the cell cycle [32,33], was used to arrest RASFs at $\mathrm{G}_{2} / \mathrm{M}$ phase ( $\sim \mathrm{n}$ DNA). Cell cycle analysis of earlycultured RASFs ( $10^{4}$ cells) treated with nocodazol for 18 hours showed only a marginal increase of proliferating RASFs to $\mathrm{G}_{2} / \mathrm{M}$ phase, from $7.95 \%$ to $11.41 \%$, corresponding to $\sim 4$ n DNA content (Figure 2a, representative histogram, and Figure $2 b, n=5$ ). Similar results were obtained after incubation with nocodazol for 24 and 36 hours (data not shown). $\mathrm{MHH}$ ES-1 cells, an established Ewing sarcoma cell line [34], were used as a positive control for arresting cells in $G_{2} / M$ phase after incubation with nocodazol. $\mathrm{G}_{2} / \mathrm{M}$-phase-arrested $\mathrm{MHH}$ ES-1 cells showed a $20 \%$ increase in the $G_{2} / M$ phase, from $46 \%$ to $66 \%$ (data not shown). HU, which inhibits reversible DNA synthesis in mammalian cells without affecting RNA and protein synthesis, was used to synchronise RASFs in $G_{0} / G_{1}$ phase [35]. The effect of $\mathrm{HU}$ on the cell cycle of RASFs was illustrated in Figure 2c (representative histogram) and Figure $2 d(n=3)$. Cell cycle analysis of RASFs treated with a single exposure to $0.5 \mathrm{mM} \mathrm{HU}$ for 6 hours (time 0 hours) showed an accumulation of RASFs in $\mathrm{G}_{0} / \mathrm{G}_{1}$ phase $(93.39 \%$, corresponding to $\sim 2 \mathrm{n} D N A, n=3$ ), indicating that the cell population remained highly synchronised. Figure $2 \mathrm{c}$ and $2 \mathrm{~d}$ also illustrated the cell cycle of RASFs after various hours after reversal of $\mathrm{HU}$. Analysis of cell cycle 18, 24, 30, 42, and 48 hours after $\mathrm{HU}$ exposure showed a decrease of RASFs in $\mathrm{G}_{0} /$ $\mathrm{G}_{1}$ phase until $66.24 \%(-27.15 \%$, after 24 hours, $n=3)$ with simultaneous increase of proliferating RASFs in $S$ phase, reaching a maximum at 24 hours $(+11.55 \%, n=3)$, and $G_{2} / M$ phase, reaching a maximum at 30 hours $(+25.53 \%, \sim 4 n$ DNA, $n=3$ ). Forty-two hours after $\mathrm{HU}$ exposure, cell cycle analysis confirmed an increase of RASFs in $\mathrm{G}_{0} / \mathrm{G}_{1}$ phase back to $87.18 \%$, and after 48 hours to $89.83 \%$, indicating that cell division commenced between 30 and 48 hours. No higher degree of synchronisation was induced by a subsequent second exposure to HU (data not shown). In addition, RASFs were arrested in $G_{0} / G_{1}$ phase through serum deprivation using ITS supplement. As illustrated in Figure 2e (representative histogram) and Figure $2 f(n=3)$, early-cultured RASFs became arrested at $G_{0} / G_{1}$ phase after 8 to 10 days of incubation with ITS medium. The initial rate of proliferating RASFs decreased from $11.14 \%$ to $8.56 \%$, or $7.96 \%$ (corresponding to $<2 \mathrm{n}$ DNA, from $0 \mathrm{~d}$ to $8 \mathrm{~d}$, and $10 \mathrm{~d}, \mathrm{n}=3$ ). Subsequent incubation for another one or two days with complete DMEM resulted in an increase of proliferating RASFs to $25.95 \%(<2$ n DNA, 9 days of ITS medium/1 day of complete medium, 9/1 d) or $22.34 \%(9 / 2 \mathrm{~d})$. Maximum of RASFs in $S$ phase was reached at day $9 / 1(+12.02 \%, \mathrm{n}=3)$ and in $\mathrm{G}_{2} / \mathrm{M}$ phase at 
day $9 / 2(+11.3 \%, n=3)$. These results suggest that only a small population of early-cultured RASFs proliferate.

\section{Susceptibility of rheumatoid arthritis synovial fibroblasts to FasL- and TRAIL-induced apoptosis}

Next, we analysed the cell cycle dependency of FasL- and TRAIL-induced programmed cell death of RASFs in vitro. We found that higher-proliferating RASFs (50\% of confluency) from different patients were less sensitive to TRAIL-induced apoptosis than lower-proliferating RASFs ( $80 \%$ of confluency) and even significantly less sensitive when confluent RASFs (100\% confluent) were used as measured by Cell Death Detection (ELISAPlus). As Figure 3a illustrates, the photometric enzyme immunoassay for the detection of cytoplasmic histone-associated DNA fragments showed a reduction from 3.35 relative fluorescence units (RFU) (confluent RASFs) to 1.55 RFU (-53\%, lower-proliferating RASFs) or to $1.0 \mathrm{RFU}$ ($70.15 \%$, higher-proliferating RASFs, data are presented as optical density (OD)/OD untreated RASFs, $n=7$ ). Similar observations were made when RASFs in different density states were treated with FasL. Measurement of the activities of caspase-3 and caspase-7, key effectors of apoptosis in mammalian cells, revealed that higher-proliferating RASFs $(50 \%$ of confluency) were less sensitive to FasL-induced apoptosis than lower-proliferating RASFs ( $80 \%$ of confluency) and confluent RASFs (Figure 3b). A reduction from $6.79 \times 10^{4} \mathrm{RFU}$ (confluent RASFs) to $5.26 \times 10^{4}$ RFU (-22.5\%, lower-proliferating RASFs) and to $2.8 \times 10^{4} \mathrm{RFU}(-59 \%$, higher-proliferating RASFs, $n=3$ ) was observed. Furthermore, highly synchronised RASFs in S phase ( $\mathrm{HU}$, time 24 hours, Figure 2c,d) and in $\mathrm{G}_{2} / \mathrm{M}$ phase (time 30 hours) were less sensitive to TRAILinduced apoptosis than synchronised RASFs in $\mathrm{G}_{0} / \mathrm{G}_{1}$ phase (time 0 hours, Figure $3 \mathrm{c}$ ). A reduction from $4.84 \times 10^{4} \mathrm{RFU}$ (HU/O hours, $\mathrm{n}=5$ ) to $1.83 \times 10^{4} \mathrm{RFU}(-62.2 \%, \mathrm{HU} / 24$ hours, $n=5)$ or to $1.93 \times 10^{4} \mathrm{RFU}(-60.13 \%, \mathrm{HU} / 30$ hours, $n=5)$ was observed by measurement of the activities of caspase- 3 and caspase-7. Similar results were obtained after measurement of FasL-induced apoptosis. Compared with RASFs synchronised in $\mathrm{G}_{0} / \mathrm{G}_{1}$ phase $\left(7.06 \times 10^{4} \mathrm{RFU}, \mathrm{n}=3\right.$, Figure $\left.3 \mathrm{~d}\right)$, RASFs synchronised in $\mathrm{S}$ phase showed a reduced apoptotic response of $1.2 \times 10^{4} \mathrm{RFU}(-83.01 \%, \mathrm{n}=3)$ and RASFs synchronised in $\mathrm{G}_{2} / \mathrm{M}$ phase showed a reduced apoptotic response of $1.45 \times 10^{4} \mathrm{RFU}(-79.5 \%, \mathrm{n}=3)$. Moreover, RASFs arrested in $G_{0} / G_{1}$ phase through serum deprivation using ITS medium ( $8 \mathrm{~d}$ ) were more sensitive to TRAIL- and FasL-induced apoptosis than proliferating RASFs in $S$ phase $(9 / 1 \mathrm{~d})$ or in $\mathrm{G}_{2} / \mathrm{M}$ phase ( $9 / 2 \mathrm{~d}$, Figure $\left.3 e, f\right)$. TRAlL-induced caspase-3/7 activities decreased from $8.62 \times 10^{4} \mathrm{RFU}$ in RASFs arrested in $\mathrm{G}_{0} / \mathrm{G}_{1}$ phase to $1.15 \times 10^{4} \mathrm{RFU}(-86.6 \%$, $\mathrm{n}=3$ ) in RASFs arrested in S phase and to $1.54 \times 10^{4} \mathrm{RFU}(-$ $82.1 \%, n=3$ ) in RASFs arrested in $\mathrm{G}_{2} / \mathrm{M}$ phase. Again, comparable results were obtained by measurement of FasLinduced programmed cell death. Figure $3 f$ illustrates a reduction from $1.14 \times 10^{6} \mathrm{RFU}\left(\mathrm{G}_{0} / \mathrm{G}_{1}\right.$ phase, $\left.8 \mathrm{~d}\right)$ to $0.61 \times 10^{5}$ RFU $(-94.64 \%$, S phase, $9 / 1 \mathrm{~d})$ and to $5.52 \times 10^{5} \mathrm{RFU}(-$ $51.84 \%, G_{2} / M$ phase, $9 / 2$ d). Unless otherwise noted, all data

Figure 1

(a)

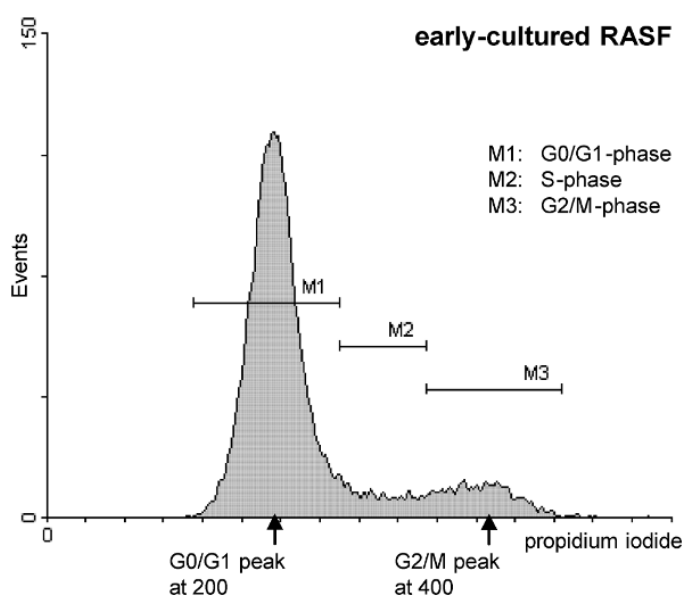

(b)
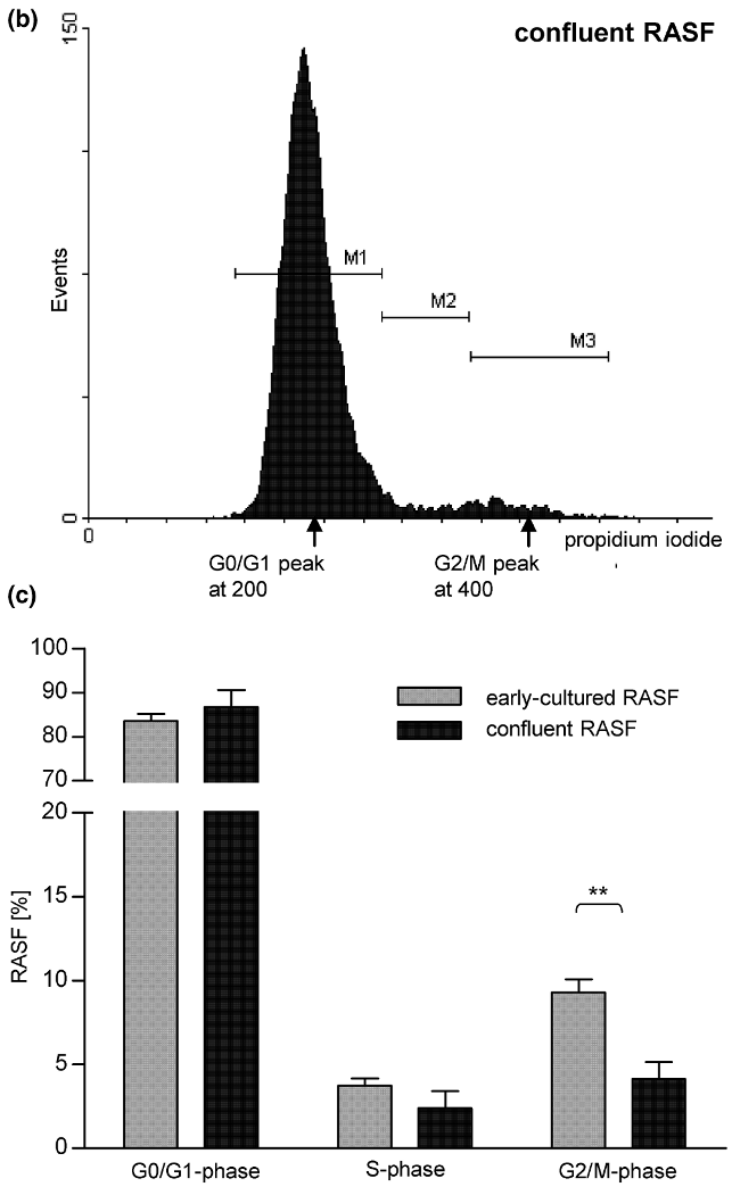

Proliferation capacity of rheumatoid arthritis synovial fibroblasts (RASFs). (a) Early-cultured RASFs exhibit only a very low proliferation rate in vitro $\left(>2 \mathrm{n}\right.$ DNA equates $S$ phase and $\mathrm{G}_{2} / \mathrm{M}$ phase, representative histogram). 2 n DNA (arrow at 200) refers to the normal DNA content of interphase $\left(\mathrm{G}_{0} / \mathrm{G}_{1}\right.$ phase) RASFs [32]. $4 \mathrm{n}$ DNA (arrow at $\mathrm{G}_{2} / \mathrm{M}$ peak at 400 ) refers to twice the amount of $D N A$ in $\mathrm{G}_{2} / \mathrm{M}$ compared with $G_{0} / G_{1}$ phase. (b) Decrease in proliferation rate in confluent RASFs. (c) Quantitative analysis. Values are mean \pm standard deviation as a percentage of early-cultured and confluent RASFs obtained from 11 or 6 individual patients with rheumatoid arthritis. ${ }^{\star \star} P<0.01$. 
(a)

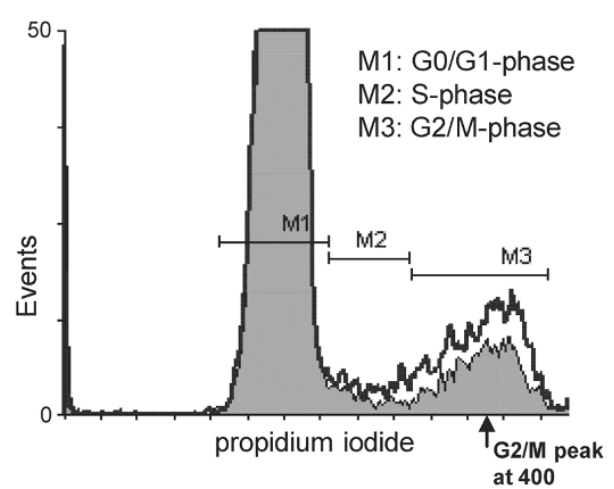

(c)

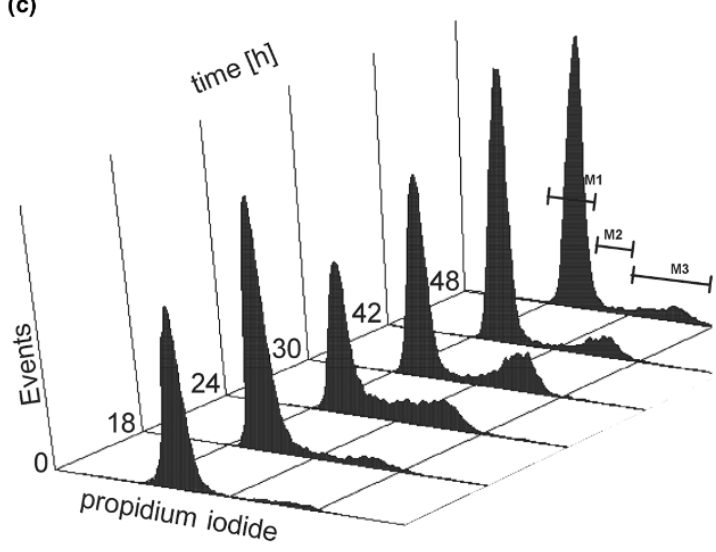

(e)

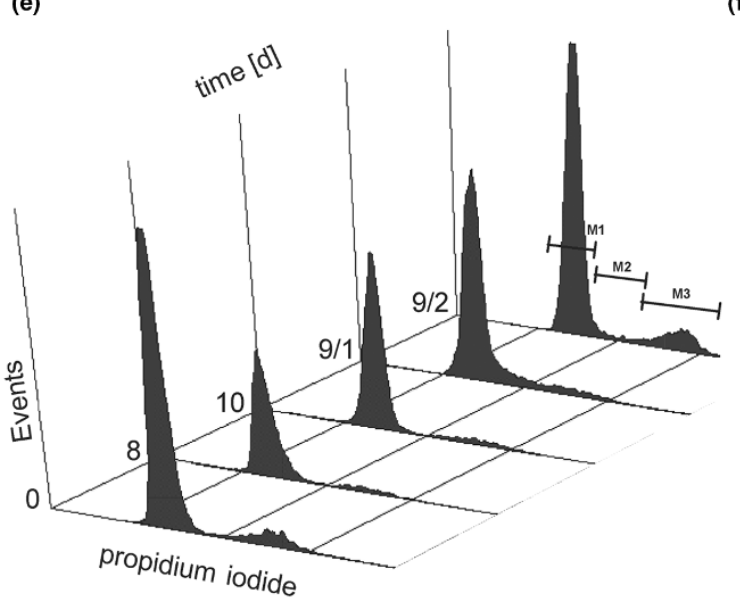

(b)

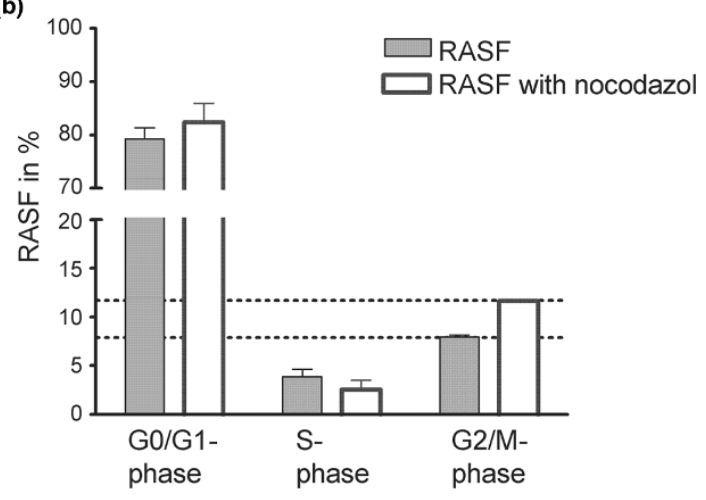

(d)

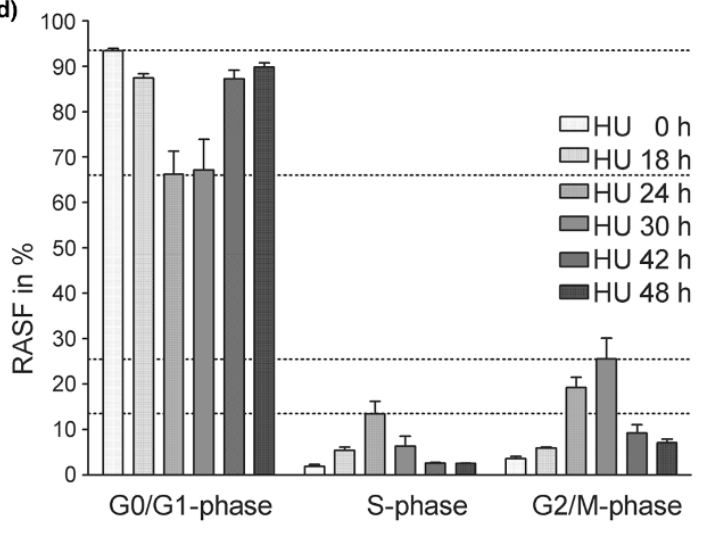

(f)

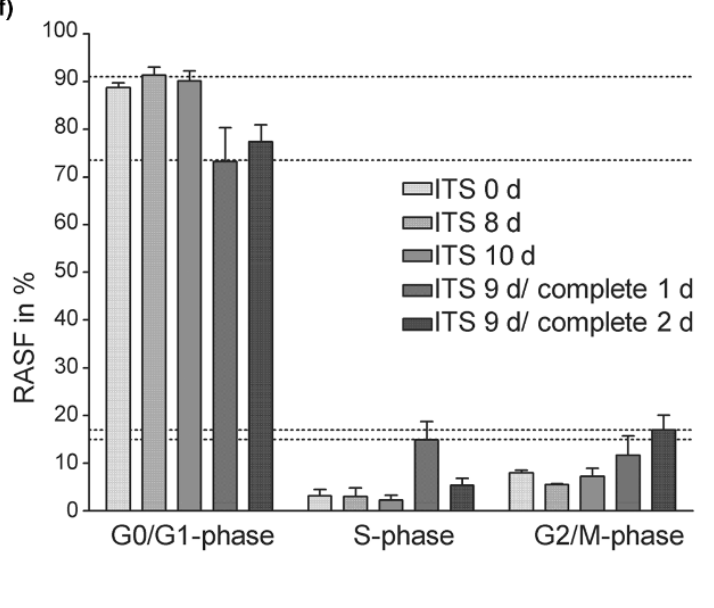

Effects of synchronisation and cell cycle arrest on proliferation of rheumatoid arthritis synovial fibroblasts (RASFs). (a) The effect of nocodazol on the cell cycle of early-cultured RASFs. Treatment of higher-proliferating RASFs with nocodazol $(2.5 \mu \mathrm{g} / \mathrm{ml}, 18$ hours) resulted in a marginal increase of RASFs arrested in $\mathrm{G}_{2} / \mathrm{M}$ phase ( $4 \mathrm{nDNA}$ at $\mathrm{G}_{2} / \mathrm{M}$ peak, black line, representative histogram). (b) Quantitative analysis. Values are mean \pm standard deviation as a percentage of RASFs treated/untreated with nocodazol obtained from 3 individual patients with RA. (c) Effects of hydroxyurea $(\mathrm{HU})$ on cell cycle of RASFs were illustrated in a representative three-dimensional histogram with the $y$-axis (time in hours) pointing away from the observer. RASFs treated with $\mathrm{HU}$ for 6 hours (time 0 hours) showed an accumulation of RASFs in $\mathrm{G}_{0} / \mathrm{G}_{1}$ phase. Analysis of cell cycle 18, 24, and 30 hours after $\mathrm{HU}$ exposure showed a decrease of RASFs in $G_{0} / G_{1}$ phase with a simultaneous increase of proliferating RASFs in $S$ phase and $G_{2} /$ $M$ phase, indicating that the cell population remained highly synchronised. Cell cycle analysis after 42 and 48 hours confirmed an increase of RASFs in $G_{0} / G_{1}$ phase, indicating that cell division commenced between 30 and 48 hours. (d) Quantitative analysis as mean \pm standard deviation. (e) Early-cultured RASFs became arrested at $G_{0} / G_{1}$ phase after 8 to 10 days of incubation with ITS medium. Subsequent incubation for another 1 or 2 days with complete Dulbecco's modified Eagle's medium (9/1, 9/2 days) resulted in an increase of proliferating RASFs. Bar graphs in frames on right show quantitative analysis. Values are presented as mean \pm standard deviation of percentages of RASFs obtained from at least three individual patients with rheumatoid arthritis. Representative three-dimensional histogram. (f) Quantitative analysis. 
in Figure 3 are presented as OD/OD unstimulated RASFs. Staurosporin-treated cells served as a positive control. We hypothesise that the susceptibility of RASFs to receptor-mediated apoptosis depends on the proliferation state of these cells in vitro.

\section{Expression of Fas and TRAIL receptors on rheumatoid arthritis synovial fibroblasts}

Finally, to investigate whether altered expression of death receptors may provide an explanation for differences in the susceptibility of RASFs to FasL- and TRAIL-induced apoptosis, the expression of Fas- and TRAIL-receptor changes during cell cycle progression, synchronisation, or at cell cycle arrest was examined. As shown by flow cytometry, TRAIL-R1 and TRAIL-R2 were expressed constitutively on higher-proliferating RASFs in vitro, whereas TRAIL-R3 and TRAIL-R4 were not detectable. The expression levels did not change in confluent RASFs (Figure $4 a$, representative histogram, $n=3$ ). In addition, expression of these receptors was unaltered when RASFs were treated for 18 hours with $100 \mathrm{ng} / \mathrm{ml}$ TRAIL (data not shown). Furthermore, cell surface expression of TRAIL receptors on RASFs remained unchanged in RASFs synchronised with HU (Figure 4b, representative histogram, $n=3$ ) or on RASFs arrested by using ITS medium (data not shown).

Fas (CD95) is a well-known apoptosis-signalling cell surface receptor belonging to the TNF receptor family [36]. To investigate the susceptibility of RASFs to FasL-mediated apoptosis, cell surface expression of Fas on RASFs was determined by flow cytometry in vitro. In agreement with data from Kobayashi and colleagues [37], who showed surface expression of Fas on RA synoviocytes, Fas was constitutively expressed on higher-proliferating RASFs (data not shown). Cell surface expression remained unchanged in confluent RASFs and under all investigated conditions (data not shown).

\section{Discussion}

A decreased susceptibility to apoptosis and synovial proliferation has been described to contribute to RASF hyperplasia $[5,10,11,14,38,39]$. In this context, the TRAIL receptor/TRAIL system and the Fas/FasL system have raised much interest. Increasing evidence suggests that RASFs are relatively resistant to FasL-induced apoptosis in vitro $[10,11,40]$. Specifically, several studies with cultured RASFs showed that synoviocytes from rheumatoid synovium tissue express functional Fas $[8,17,18]$ and that Fas activation induces apoptosis only in a small population of cells, even though the Fas/FasL system seems to be incapable of eliminating cells in proliferative RA synovium $[8,18,37,40,41]$. The data concerning TRAIL appear to be controversial $[25,26,40]$. Ichikawa and colleagues [26] analysed the effect of TRAIL on RASFs and reported an increased DR5 expression and an induction of DR5-mediated apoptosis up to $80 \%$, although varying levels of apoptosis were induced by TRAIL using different RASF cultures. In agreement with these findings, Miranda-Carus and colleagues
[38] analysed fibroblasts of 50 RA synovial fluid samples and showed that these fibroblasts underwent apoptosis when treated in vitro with an agonistic anti-DR5 antibody. In contrast, Morel and colleagues [25] proposed that TRAIL might have two different effects on RASFs, namely an initial rapid induction of apoptosis of up to 30\% within the first 24 hours followed by an increase in the proliferation [25]. In addition, it is well documented that, depending on the cellular system, TRAIL can promote both proliferation and apoptosis, as has been established for other members of the TNF cytokine family [42]. In the present study, we hypothesised that the susceptibility of RASFs to receptor-mediated apoptosis depends on the proliferation status of these cells and, therefore, analysed the cell cycle dependency of FasL- and TRAIL-induced programmed cell death of RASFs in vitro.

Our results indicate that freshly prepared RASFs exhibit only a very low proliferation rate in vitro. The proliferation rate decreases further over time, particularly when RASFs become confluent. Furthermore, we describe for the first time that up to $65 \%$ of RASFs exhibit a $\mathrm{G}_{0} / \mathrm{G}_{1}$-phase arrest in vitro. Moreover, our study shows that early-cultured RASFs are less sensitive to TRAIL- and FasL-induced apoptosis than late-cultured RASFs and far less sensitive than 100\% confluent RASFs. The difference in sensitivity to TRAIL- and FasL-mediated apoptosis between early-cultured and confluent RASFs is not due to differences in the surface expression of Fas and TRAIL receptors. Rather, the susceptibility clearly depended on the cell cycle of these cells as RASFs that were synchronised in S phase or $G_{2} / M$ phase were less sensitive to TRAIL-induced apoptosis than RASFs that were arrested in $G_{0} / G_{1}$ phase. These results suggest an inverse correlation between cell proliferation and apoptosis. However, how the proliferation influences TRAIL- and FasL-mediated synovial cell death remains unclear. Miyashita and colleagues [43] proposed that the serine/threonine protein kinase Akt, which affects several important cellular functions (including cell growth, cell cycle entry, migration, and cell survival), is an endogenous inhibitor of the TRAIL-mediated synovial cell apoptotic pathway. Furthermore, numerous data have shown that activation of Akt inhibits TRAIL-mediated apoptosis in various cancer cells and Akt has been shown to be overexpressed and activated in rheumatoid synovial cells in situ [44-47]. Therefore, it might be speculated that there is a correlation between cell proliferation and apoptosis, which may be regulated by the Akt pathway, but clearly further studies are required to elaborate on these observations.

\section{Conclusion}

In summary, we have shown that a relatively high number of RASFs are arrested in $\mathrm{G}_{0} / \mathrm{G}_{1}$ phase. Furthermore, our data indicate that the sensitivity to TRAIL- or FasL-mediated apoptosis may be closely linked to synovial proliferation. These findings will further enhance our understanding of the pathophysiology of RA. 

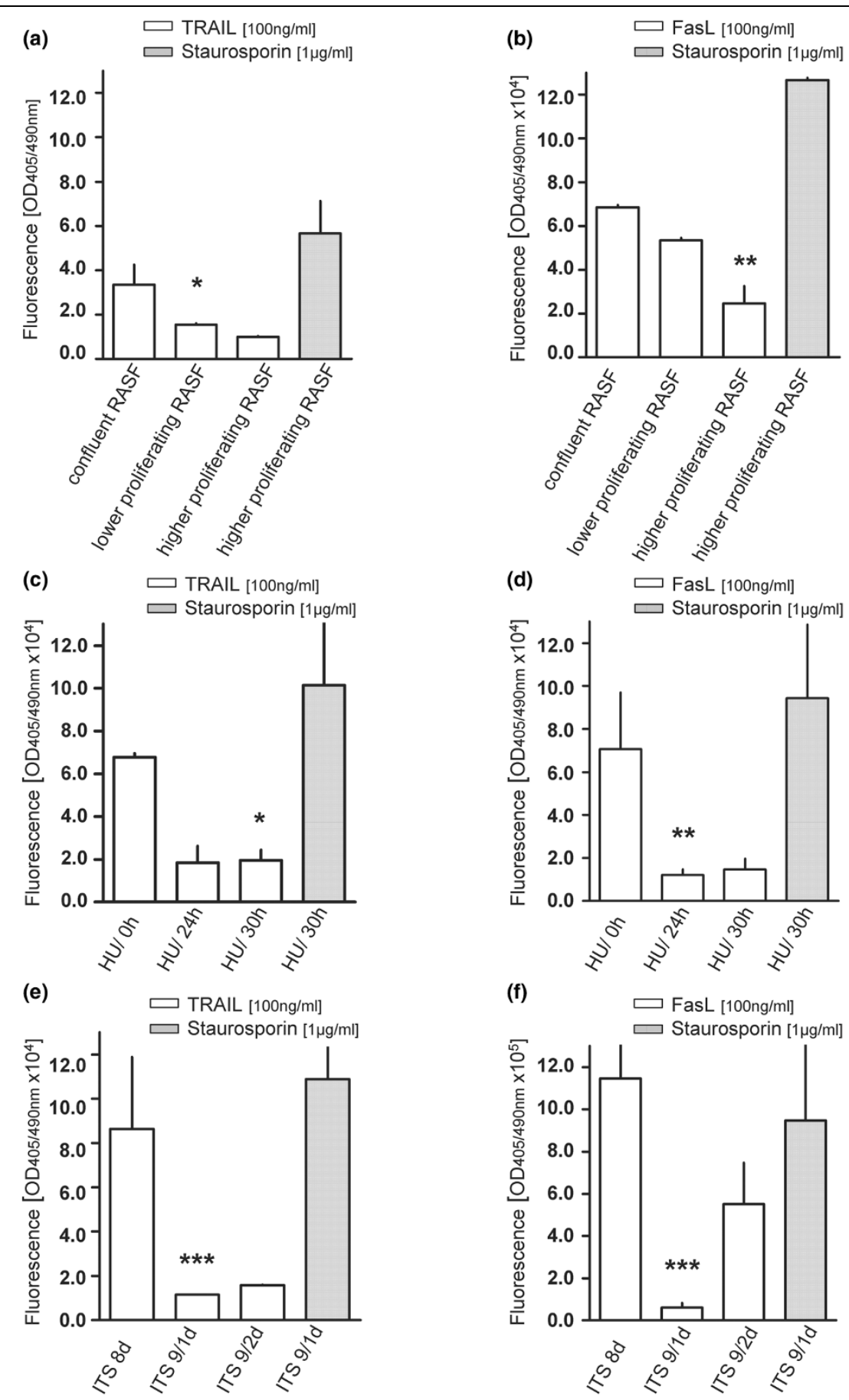

Susceptibility of proliferating rheumatoid arthritis synovial fibroblasts (RASFs) to Fas ligand (FasL)-induced and tumour necrosis factor-related apoptosis-inducing ligand (TRAIL)-induced apoptosis. (a) As assessed by Cell Death Detection (ELISAPlus), higher-proliferating RASFs (50\% of confluency) were less sensitive to TRAIL-induced apoptosis than lower-proliferating RASFs ( $80 \%$ of confluency) and significantly less sensitive than confluent RASFs (100\% confluent). (b) As revealed by the Apo-ONE ${ }^{\circledR}$ Homogeneous Caspase-3/7 Assay, higher-proliferating RASFs showed lower activities of caspase-3 and caspase-7 after induction of apoptosis with FasL than less-proliferating RASFs and confluent RASFs. Highly synchronised RASFs in S phase $(\mathrm{HU} / 24 \mathrm{~h})$ or $\mathrm{G}_{2} / \mathrm{M}$ phase $(\mathrm{HU} / 30 \mathrm{~h}$ ) were less sensitive to TRAlL-induced (c) and FasL-induced (d) apoptosis than synchronised RASFs in $\mathrm{G}_{0} / \mathrm{G}_{1}$ phase (HU/O h), as measured by the Apo-ONE ${ }^{\circledR}$ Homogeneous Caspase-3/7 Assay. Moreover, RASFs arrested in $\mathrm{G}_{0} / \mathrm{G}_{1}$ phase through serum deprivation using insulin-transferrin-sodium selenite (ITS) medium ( $8 \mathrm{~d}$ ) were more sensitive to TRAIL-induced (e) and FasL-induced (f) apoptosis than proliferating RASFs in $S$ phase $(9 / 1 \mathrm{~d})$ or $\mathrm{G}_{2} / \mathrm{M}$ phase $(9 / 2 \mathrm{~d})$. Staurosporin-induced apoptosis was measured as a positive control. All values are mean \pm standard deviation of fluorescence/fluorescence of unstimulated RASFs from at least three independent patients with rheumatoid arthritis. ${ }^{\star} P<0.05,{ }^{\star \star} P<0.01,{ }^{\star \star \star} P<0.001$. 
Arthritis Research \& Therapy Vol 11 No 1 Bundt et al.

Figure 4
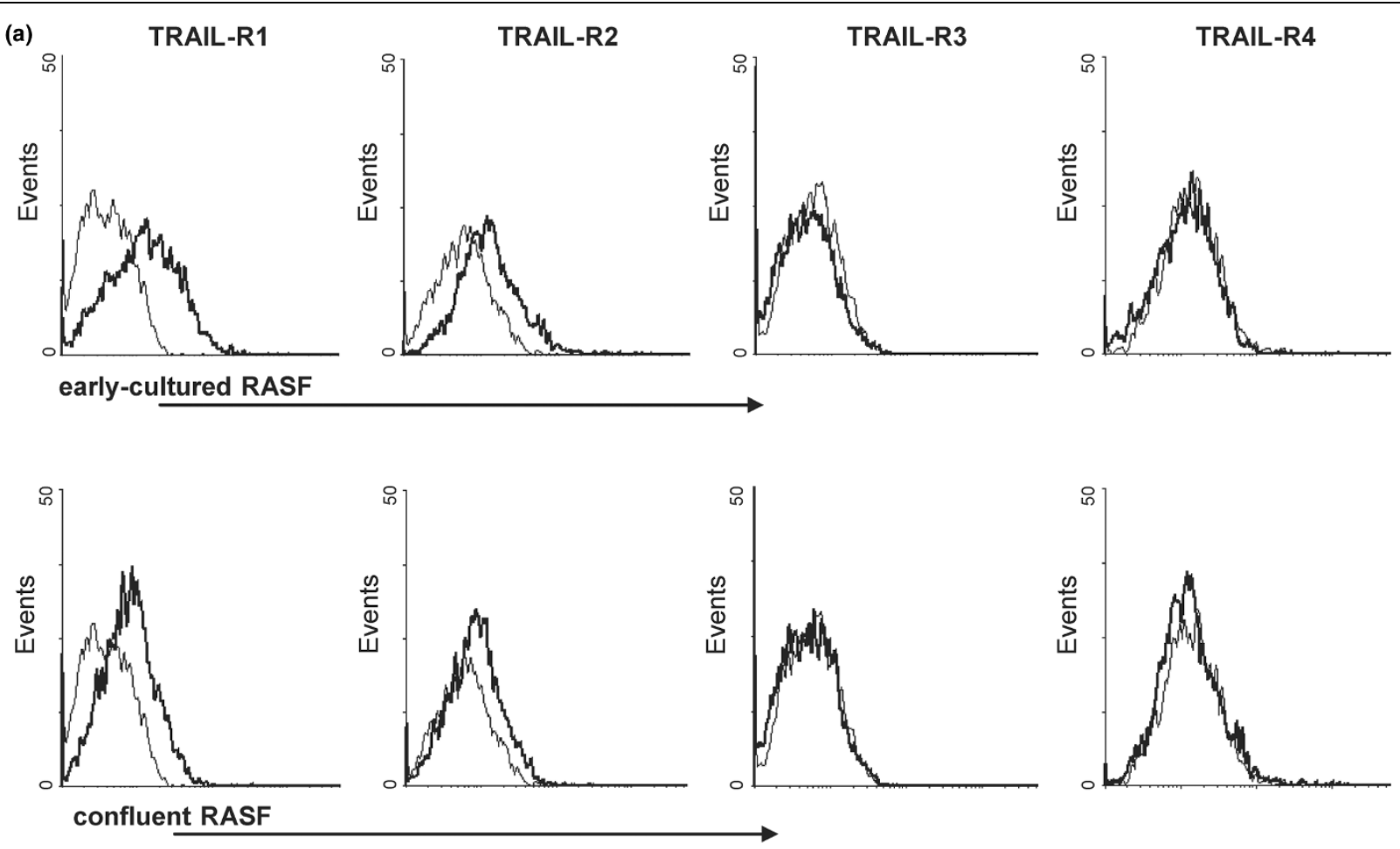

(b)
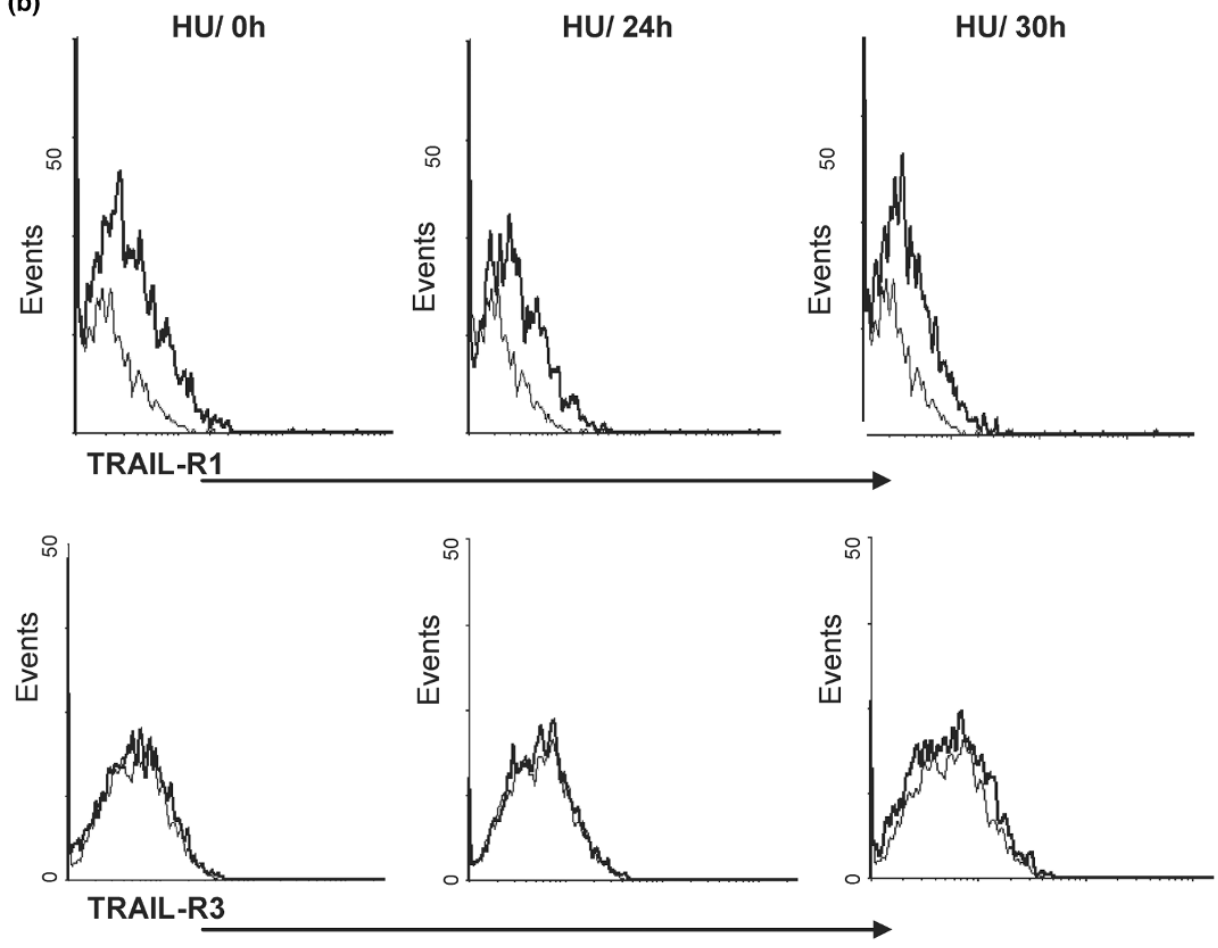

Surface expression of tumour necrosis factor-related apoptosis-inducing ligand (TRAIL) receptors on rheumatoid arthritis synovial fibroblasts (RASPs). (a) Staining of TRAIL receptors, as analysed by flow cytometry, showed constitutive surface expression of TRAIL-R1 and TRAIL-R2 on RASPs in vito. TRAIL-R3 and TRAIL-R4 were not detectable. The expression levels did not change in confluent RASPs. (b) Furthermore, cell surface expression of TRAIL-R1 and TRAIL-R3 on RASPs remained unchanged in RASFs synchronised with hydroxyurea (HU). Representative histograms of three separate experiments are shown.

Page 8 of 10

(page number not for citation purposes) 


\section{Competing interests}

The authors declare that they have no competing interests.

\section{Authors' contributions}

NP helped to design research, to perform research, and to analyse data and wrote the paper. MAP, CW, and TP helped to design research, to perform research, and to analyse data. $\mathrm{IM}$ helped to design research and to analyse data. SS, CF, KN, and CS helped to perform research. FvV helped to perform research and to analyse data. All authors read and approved the final manuscript.

\section{Acknowledgements}

The authors thank Borna Truckenbrod and Vera Eckervogt for technical assistance and Jennifer Gerding for observant reading of the manuscript. This work was funded in part by the Deutsche Forschungsgemeinschaft (DFG) (Pa689/2 and Pa689/3), the Assoziation für Rheumatologische Orthopädie (ARO) of the German Society of Rheumatology (DGRh), and the Interdisciplinary Center for Clinical Research (IZKF) of the University of Muenster.

\section{References}

1. Muller-Ladner U, Gay RE, Gay S: Cellular pathways of joint destruction. Curr Opin Rheumatol 1997, 9:213-220.

2. Fassbender HG: Histomorphological basis of articular cartilage destruction in rheumatoid arthritis. Coll Relat Res 1983, 3:141-155.

3. Gay S, Gay RE, Koopman WJ: Molecular and cellular mechanisms of joint destruction in rheumatoid arthritis: two cellular mechanisms explain joint destruction? Ann Rheum Dis 1993, 52 Suppl 1:S39-S47.

4. Meinecke I, Rutkauskaite E, Gay S, Pap T: The role of synovial fibroblasts in mediating joint destruction in rheumatoid arthritis. Curr Pharm Des 2005, 11:563-568.

5. Pap T, Muller-Ladner U, Gay RE, Gay S: Fibroblast biology. Role of synovial fibroblasts in the pathogenesis of rheumatoid arthritis. Arthritis Res 2000, 2:361-367.

6. Perlman H, Pagliari LJ, Volin MV: Regulation of apoptosis and cell cycle activity in rheumatoid arthritis. Curr Mol Med 2001, 1:597-608.

7. Riedl SJ, Shi Y: Molecular mechanisms of caspase regulation during apoptosis. Nat Rev Mol Cell Biol 2004, 5:897-907.

8. Firestein GS, Yeo M, Zvaifler NJ: Apoptosis in rheumatoid arthritis synovium. J Clin Invest 1995, 96:1631-1638.

9. Pap T: [Regulation of apoptosis in aggressive fibroblasts]. $Z$ Rheumatol 2007, 66:239-240. 242.

10. Hayashi S, Miura Y, Nishiyama T, Mitani M, Tateishi K, Sakai Y, Hashiramoto A, Kurosaka M, Shiozawa S, Doita M: Decoy receptor 3 expressed in rheumatoid synovial fibroblasts protects the cells against Fas-induced apoptosis. Arthritis Rheum 2007, 56:1067-1075.

11. Meinecke I, Cinski A, Baier A, Peters MA, Dankbar B, Wille A, Drynda A, Mendoza H, Gay RE, Hay RT, Ink B, Gay S, Pap T: Modification of nuclear PML protein by SUMO-1 regulates Fasinduced apoptosis in rheumatoid arthritis synovial fibroblasts. Proc Natl Acad Sci USA 2007, 104:5073-5078.

12. Kobayashi T, Okamoto $K$, Kobata $T$, Hasunuma T, Sumida T, Nishioka K: Tumor necrosis factor alpha regulation of the FASmediated apoptosis-signaling pathway in synovial cells. Arthritis Rheum 1999, 42:519-526.

13. Wakisaka S, Suzuki N, Takeba $Y$, Shimoyama $Y$, Nagafuchi H, Takeno M, Saito N, Yokoe T, Kaneko A, Asai T, Sakane T: Modulation by proinflammatory cytokines of Fas/Fas ligand-mediated apoptotic cell death of synovial cells in patients with rheumatoid arthritis (RA). Clin Exp Immunol 1998, 114:119-128.

14. Palao G, Santiago B, Galindo M, Paya M, Ramirez JC, Pablos JL: Down-regulation of FLIP sensitizes rheumatoid synovial fibroblasts to Fas-mediated apoptosis. Arthritis Rheum 2004, 50:2803-2810.
15. Baier A, Meineckel I, Gay S, Pap T: Apoptosis in rheumatoid arthritis. Curr Opin Rheumatol 2003, 15:274-279.

16. Franz JK, Pap T, Hummel KM, Nawrath M, Aicher WK, Shigeyama Y, Muller-Ladner U, Gay RE, Gay S: Expression of sentrin, a novel antiapoptotic molecule, at sites of synovial invasion in rheumatoid arthritis. Arthritis Rheum 2000, 43:599-607.

17. Nishioka K, Hasunuma T, Kato T, Sumida T, Kobata T: Apoptosis in rheumatoid arthritis: a novel pathway in the regulation of synovial tissue. Arthritis Rheum 1998, 41:1-9.

18. Nakajima $T$, Aono $H$, Hasunuma $T$, Yamamoto $K$, Shirai $T$, Hirohata $\mathrm{K}$, Nishioka K: Apoptosis and functional Fas antigen in rheumatoid arthritis synoviocytes. Arthritis Rheum 1995, 38:485-491.

19. Asahara $\mathrm{H}$, Hasumuna $\mathrm{T}$, Kobata $\mathrm{T}$, Yagita $\mathrm{H}$, Okumura $\mathrm{K}$, Inoue $\mathrm{H}$, Gay S, Sumida T, Nishioka K: Expression of Fas antigen and Fas ligand in the rheumatoid synovial tissue. Clin Immunol Immunopathol 1996, 81:27-34.

20. Baetu TM, Hiscott J: On the TRAIL to apoptosis. Cytokine Growth Factor Rev 2002, 13:199-207.

21. Emery JG, McDonnell P, Burke MB, Deen KC, Lyn S, Silverman C Dul E, Appelbaum ER, Eichman C, DiPrinzio R, Dodds RA, James $\mathrm{IE}$, Rosenberg M, Lee JC, Young PR: Osteoprotegerin is a receptor for the cytotoxic ligand TRAIL. J Biol Chem 1998, 273:14363-14367.

22. Vitovski S, Phillips JS, Sayers J, Croucher PI: Investigating the interaction between osteoprotegerin and receptor activator of NF-kappaB or tumor necrosis factor-related apoptosis-inducing ligand: evidence for a pivotal role for osteoprotegerin in regulating two distinct pathways. J Biol Chem 2007, 282:31601-31609.

23. Truneh A, Sharma S, Silverman C, Khandekar S, Reddy MP, Deen KC, McLaughlin MM, Srinivasula SM, Livi GP, Marshall LA, Alnemri ES, Williams WV, Doyle ML: Temperature-sensitive differential affinity of TRAIL for its receptors. DR5 is the highest affinity receptor. J Biol Chem 2000, 275:23319-23325.

24. Wang S, El-Deiry WS: TRAIL and apoptosis induction by TNFfamily death receptors. Oncogene 2003, 22:8628-8633.

25. Morel J, Audo R, Hahne M, Combe B: Tumor necrosis factorrelated apoptosis-inducing ligand (TRAIL) induces rheumatoid arthritis synovial fibroblast proliferation through mitogenactivated protein kinases and phosphatidylinositol 3-kinase/ Akt. J Biol Chem 2005, 280:15709-15718.

26. Ichikawa $K$, Liu W, Fleck M, Zhang $H$, Zhao L, Ohtsuka T, Wang Z, Liu D, Mountz JD, Ohtsuki M, Koopman WJ, Kimberly R, Zhou T: TRAIL-R2 (DR5) mediates apoptosis of synovial fibroblasts in rheumatoid arthritis. J Immunol 2003, 171:1061-1069.

27. Pap T, Shigeyama Y, Kuchen S, Fernihough JK, Simmen B, Gay $R E$, Billingham $M$, Gay S: Differential expression pattern of membrane-type matrix metalloproteinases in rheumatoid arthritis. Arthritis Rheum 2000, 43:1226-1232.

28. Matsue $H$, Edelbaum D, Hartmann AC, Morita A, Bergstresser PR, Yagita $\mathrm{H}$, Okumura $\mathrm{K}$, Takashima A: Dendritic cells undergo rapid apoptosis in vitro during antigen-specific interaction with CD4+ T cells. J Immunol 1999, 162:5287-5298.

29. Straus DS: Growth-stimulatory actions of insulin in vitro and in vivo. Endocr Rev 1984, 5:356-369.

30. Barros JC, Marshall CJ: Activation of either ERK1/2 or ERK5 MAP kinase pathways can lead to disruption of the actin cytoskeleton. J Cell Sci 2005, 118:1663-1671.

31. Drynda A, Quax PH, Neumann M, Laan WH van der, Pap G, Drynda S, Meinecke I, Kekow J, Neumann W, Huizinga TW, Naumann M, Konig W, Pap T: Gene transfer of tissue inhibitor of metalloproteinases- 3 reverses the inhibitory effects of TNFalpha on Fas-induced apoptosis in rheumatoid arthritis synovial fibroblasts. J Immuno/ 2005, 174:6524-6531.

32. Roumier T, Valent A, Perfettini JL, Metivier D, Castedo M, Kroemer G: A cellular machine generating apoptosis-prone aneuploid cells. Cell Death Differ 2005, 12:91-93.

33. Hsu SL, Yu CT, Yin SC, Tang MJ, Tien AC, Wu YM, Huang CY: Caspase 3, periodically expressed and activated at $\mathrm{G}_{2} / \mathrm{M}$ transition, is required for nocodazole-induced mitotic checkpoint. Apoptosis 2006, 11:765-771.

34. van Valen F, Fulda S, Truckenbrod B, Eckervogt V, Sonnemann J, Hillmann A, Rodl R, Hoffmann C, Winkelmann W, Schafer L, Dockhorn-Dworniczak B, Wessel T, Boos J, Debatin KM, Jurgens H: Apoptotic responsiveness of the Ewing's sarcoma family of tumours to tumour necrosis factor-related apoptosis-inducing ligand (TRAIL). Int J Cancer 2000, 88:252-259. 
35. Plagemann PG, Richey DP, Zylka JM, Erbe J: Thymidine transport by Novikoff rat hepatoma cells synchronized by double hydroxyurea treatment. Exp Cell Res 1974, 83:303-310.

36. Suda T, Takahashi T, Golstein P, Nagata S: Molecular cloning and expression of the Fas ligand, a novel member of the tumor necrosis factor family. Cell 1993, 75:1169-1178.

37. Kobayashi T, Okamoto K, Kobata T, Hasunuma T, Kato T, Hamada $\mathrm{H}$, Nishioka K: Differential regulation of Fas-mediated apoptosis of rheumatoid synoviocytes by tumor necrosis factor alpha and basic fibroblast growth factor is associated with the expression of apoptosis-related molecules. Arthritis Rheum 2000, 43:1106-1114.

38. Miranda-Carus ME, Balsa A, ito-Miguel M, De Ayala CP, MartinMola E: Rheumatoid arthritis synovial fluid fibroblasts express TRAIL-R2 (DR5) that is functionally active. Arthritis Rheum 2004, 50:2786-2793.

39. Harris ED Jr: Rheumatoid arthritis. Pathophysiology and implications for therapy. N Engl J Med 1990, 322:1277-1289.

40. Itoh $\mathrm{K}$, Hase H, Kojima H, Saotome K, Nishioka K, Kobata T: Central role of mitochondria and p53 in Fas-mediated apoptosis of rheumatoid synovial fibroblasts. Rheumatology (Oxford) 2004, 43:277-285.

41. Okamoto K, Fujisawa $K$, Hasunuma $T$, Kobata $T$, Sumida $T$, Nishioka K: Selective activation of the JNK/AP-1 pathway in Fasmediated apoptosis of rheumatoid arthritis synoviocytes. Arthritis Rheum 1997, 40:919-926.

42. Screaton $G, X u X N$ : $T$ cell life and death signalling via TNFreceptor family members. Curr Opin Immunol 2000, 12:316-322.

43. Miyashita T, Kawakami A, Tamai M, Izumi Y, Mingguo H, Tanaka F, Abiru S, Nakashima K, Iwanaga N, Aratake K, Kamachi M, Arima K, Ida H, Migita K, Origuchi T, Tagashira S, Nishikaku F, Eguchi K: Akt is an endogenous inhibitor toward tumor necrosis factorrelated apoptosis inducing ligand-mediated apoptosis in rheumatoid synovial cells. Biochem Biophys Res Commun 2003, 312:397-404.

44. Chen X, Thakkar H, Tyan F, Gim S, Robinson H, Lee C, Pandey SK, Nwokorie C, Onwudiwe N, Srivastava RK: Constitutively active Akt is an important regulator of TRAIL sensitivity in prostate cancer. Oncogene 2001, 20:6073-6083.

45. Gibson EM, Henson ES, Haney N, Villanueva J, Gibson SB: Epidermal growth factor protects epithelial-derived cells from tumor necrosis factor-related apoptosis-inducing ligandinduced apoptosis by inhibiting cytochrome c release. Cancer Res 2002, 62:488-496.

46. Thakkar H, Chen X, Tyan F, Gim S, Robinson H, Lee C, Pandey SK, Nwokorie C, Onwudiwe N, Srivastava RK: Pro-survival function of Akt/protein kinase B in prostate cancer cells. Relationship with TRAIL resistance. J Biol Chem 2001, 276:38361-38369.

47. Zhang HG, Wang $Y$, Xie JF, Liang X, Liu D, Yang P, Hsu HC, Ray RB, Mountz JD: Regulation of tumor necrosis factor alphamediated apoptosis of rheumatoid arthritis synovial fibroblasts by the protein kinase Akt. Arthritis Rheum 2001, 44:1555-1567. 